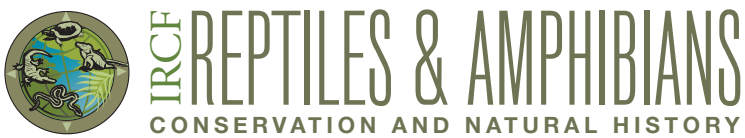

\section{Notes on Indian Star Tortoises (Geochelone elegans) Confiscated from an Old Temple in Vadodara, Gujarat, India}

\author{
Raju Vyas
}

1-Sashwat Apartment, BPC Road, Nr. Splatter Studio, Alakapuri, Vadodara-390007, Gujarat, India (razoovyas@hotmail.com)

Photographs by the author.

$\mathrm{O}$ 9 October 2016, the local forest department confiscated 21 (9 males and 12 females) Indian Star Tortoises (Geochelone elegans; Fig. 1) from the Hindu Viththalnath Temple in Mandvi, Vadodara, Gujarat, India. This is one of the oldest temple complexes in the city, built about two hundred years ago by the Gaekwads, erstwhile rulers of Vadodara. The temple's head priest indicated that tortoises are considered holy and traditionally have been retained on the premises for more than a century.

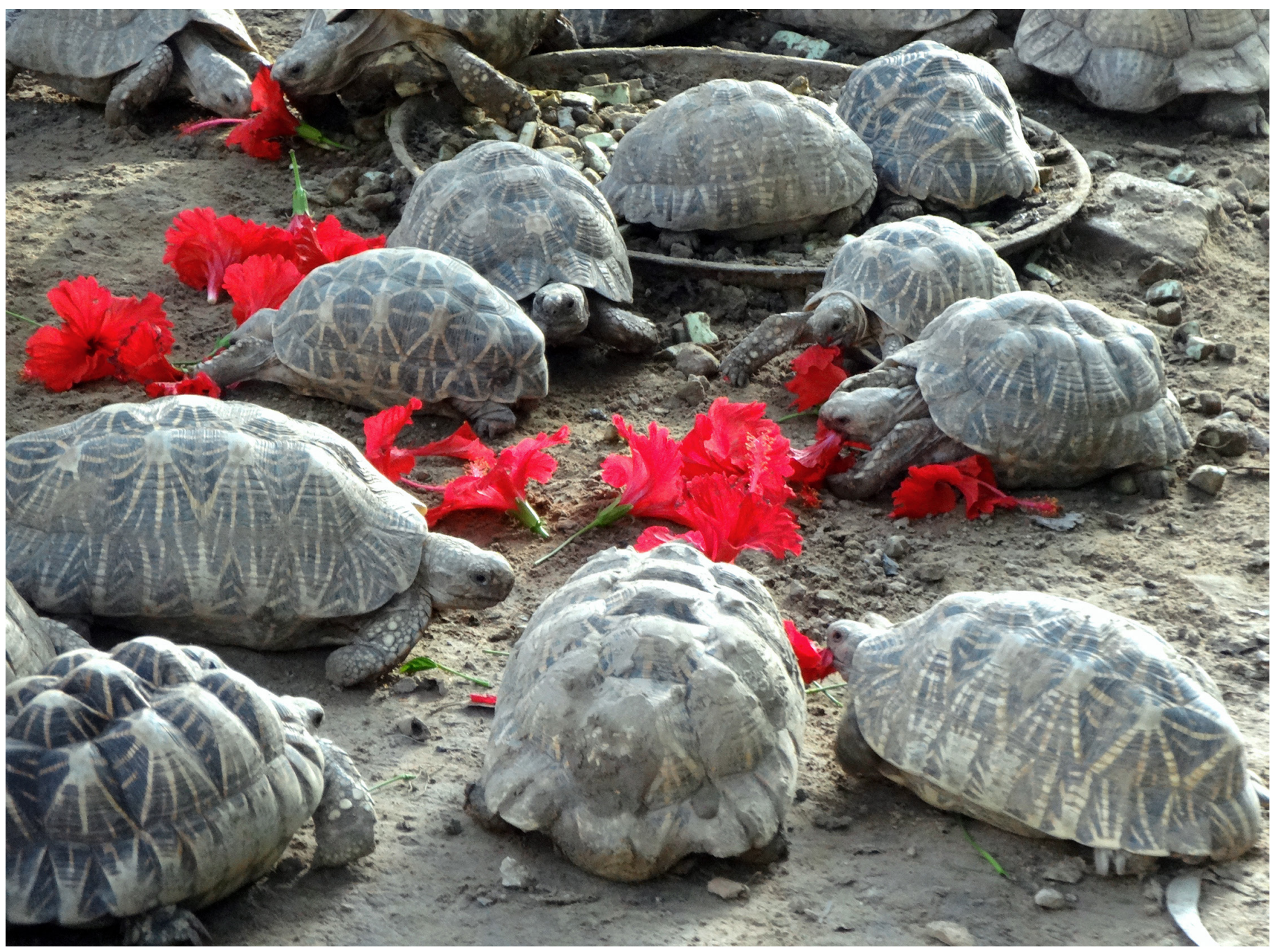

Fig. 1. Indian Star Tortoises (Geochelone elegans) feeding on hibiscus flowers at the Vithalnath Temple, Vadodara, Gujarat, India. 


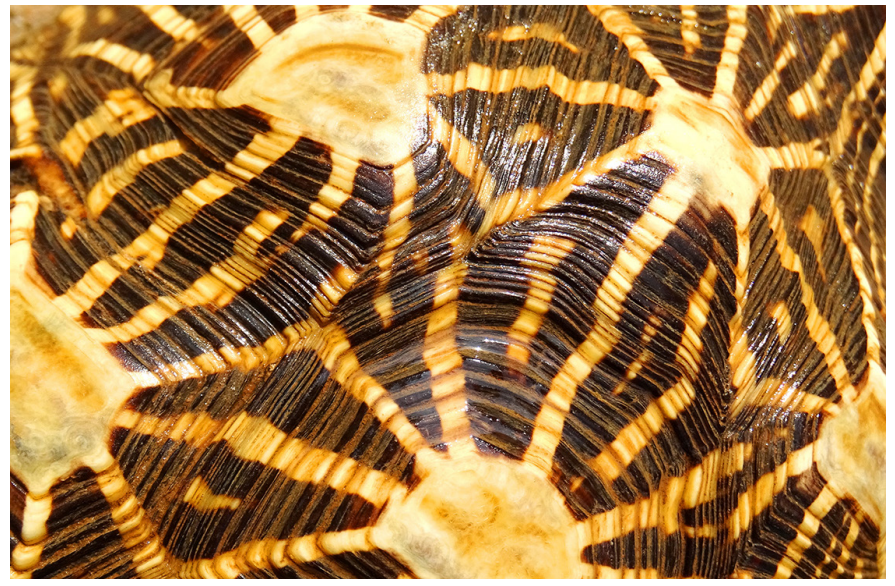

Fig. 2. Dorsal scutes of an Indian Star Tortoise (Geochelone elegans) showing the increasingly smaller growth rings along the beveled edges of the scutes.

Temple devotees revere these reptiles, worship them regularly, and look after them carefully. Most of the confiscated animals had been brought to the temple for worship by local devotees.

The claim by the head priest that these tortoises were very old and had been held captive for almost two centuries caught my attention and raised questions regarding the actual age of the tortoises. I carefully examined the confiscated animals and recorded color and weight, and measured shell size and shape using a flexible measuring tape and dial calipers. I estimated the age of each tortoise by counting growth rings on the first vertebral scute. This method has known limitations, especially when determining the age of older animals, as the one-ring-per-year rule is difficult to apply as growth slows with age, causing rings to be smaller and difficult to see. Ultimately, the last rings become indistinct and the edge of the scute becomes beveled (Fig. 2).

Results (Table 1) were not what I had been led to expect. Only ten tortoises showed signs of substantial age. The remaining eleven animals were smaller and younger. Mean (range) curved carapace length (CCL) and weight of four males was $26.1 \mathrm{~cm}(25.5-26.8 \mathrm{~cm})$ and $3.10 \mathrm{~kg}(2.90-3.40$ $\mathrm{kg}$ ), respectively, and estimated ages were $35-55$ years; corresponding values for six females were $30.4 \mathrm{~cm}(28.2-32.0$ $\mathrm{cm}), 4.13 \mathrm{~kg}(3.10-5.30 \mathrm{~kg}$ ), and $40-58$ years (Fig. 3).

Although quite large, none of the tortoises were as old as the priest had claimed. Males rarely exceed $26 \mathrm{~cm}$ CCL (Moll 1989; Fife 2007; D’Cruze et al. 2018). De Silva et al. (2017) provided ranges for CCL and weight of 69 Sri Lankan males

Table 1. Measurements, weights, and estimated ages of ten large Indian Star Tortoises (Geochelone elegans) confiscated from the Vithalnath Temple, Vadodara, Gujarat, India (measurements in $\mathrm{cm}$, weights in $\mathrm{kg}$, estimated ages in years).

\begin{tabular}{lcccccccccc} 
Sex & Male & Male & Male & Male & Female & Female & Female & Female & Female & Female \\
\hline Estimated Age & $35+$ & $48+$ & $50+$ & $55+$ & $46+$ & $42+$ & $58+$ & $54+$ & $52+$ & $40+$ \\
\hline Carapace Length - Curved & 26.5 & 26.8 & 25.5 & 25.5 & 28.2 & 28.5 & 31.5 & 32.0 & 32.0 & 30.0 \\
\hline Carapace Length - Straight & 34.0 & 35.7 & 33.2 & 33.0 & 36.0 & 37.0 & 31.8 & 39.7 & 40.0 & 37.2 \\
\hline Carapace Width - Curved & 18.5 & 18.7 & 19.0 & 18.2 & 13.0 & 16.0 & 21.0 & 22.8 & 23.5 & 19.5 \\
\hline Carapace Width - Straight & 31.0 & 33.0 & 31.7 & 32.0 & 36.0 & 38.0 & 40.4 & 41.0 & 40.8 & 36.2 \\
\hline Plastron Length - Straight & 22.5 & 24.0 & 23.0 & 22.0 & 24.0 & 24.5 & 27.5 & 26.5 & 28.0 & 25.5 \\
\hline Height & 14.4 & 14.7 & 14.0 & 12.3 & 18.0 & 14.5 & 16.5 & 15.5 & 17.0 & 16.1 \\
\hline Weight & 3.000 & 3.400 & 2.900 & 3.100 & 3.150 & 3.100 & 3.900 & 5.000 & 5.350 & 4.300 \\
\hline
\end{tabular}
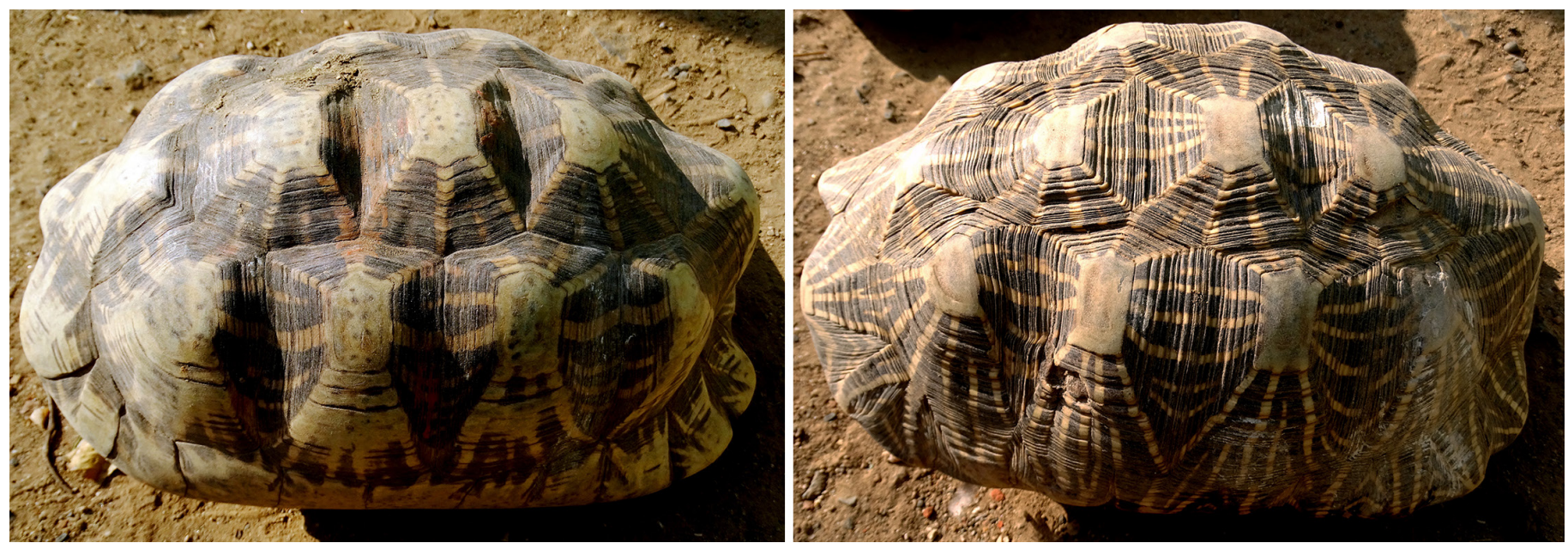

Fig. 3. Lateral views of the largest male (left) and female (right) Indian Star Tortoises (Geochelone elegans) confiscated from the Vithalnath Temple, Vadodara, Gujarat, India. 
(26.6-27.2 cm; 1.395-2.004 kg). The largest female was from Sri Lanka and measured $57.5 \mathrm{~cm}$ CCL and $14 \mathrm{~kg}$ and was 40-45 years old (based on growth rings of a coastal scute; De Silva et al. 2017). The largest female from western Indian measured $50.5 \mathrm{~cm}$ CCL and $8.960 \mathrm{~kg}$ with an estimated age of 55 years (Vyas 2011).

Many Hindu Gujaratis (= people of Gujarat State) worship reptiles (Vyas 2003), especially tortoises, as "Kurma Dev" (in Sanskrit, kurma = turtle or tortoise, dev = god) or living deities within temples (Vyas and Parasharya 2000; D’Cruze et al. 2015). In addition, some Gujaratis keep tortoises as pets. Most are unaware that all tortoises are Schedule-IV species protected under the Indian Wildlife (Protection) Act of 1972, making the possession of these animals a legal offense.

\section{Acknowledgments}

I thank Mr. Vijay Saxena (Deputy Conservator Forest, Social Forestry Division, Vadodara) for relevant permits and Mr. P. Chauhan (Range Forest Officer, Vadodara) and Mr. Nilesh Shah (forest volunteer) for their help and permission to examine the confiscated tortoises.

\section{Literature Cited}

De Silva, R., R. Wijerijeratne, K. Rodrigo, H.A.H.R. Hettiarachchi, and T. Prasad. 2017. Record of possibly the world's largest star tortoise (Geochelone elegans) from Lunugamwehera National Park, Sri Lanka. Radiata 26(3): 30-34.

D'Cruze, N., B. Singh, T. Morrison, J. Schmidt-Burbach, D.W. Macdonald, and A. Mookerjee. 2015. A star attraction: The illegal trade in Indian Star Tortoises. Nature Conservation 13: 1-19.

D’Cruze, N., A. Mookerjee, R. Vyas, D.W. Macdonald, and A. de Silva. 2018. Geochelone elegans (Schoepff 1795) - Indian Star Tortoise, Star Tortoise. In: A.G.J. Rhodin, J.B. Iverson, P.P. van Dijk, C.B. Stanford, E.V. Goode, K.A. Buhlmann, P.C.H. Pritchard, and R.A. Mittermeier (eds.), Conservation Biology of Freshwater Turtles and Tortoises: A Compilation Project of the IUCN/SSC Tortoise and Freshwater Turtle Specialist Group. Chelonian Research Monographs 5, installment 12: 106.1-13.

Fife, J.D. 2007. Star Tortoises: The Natural History, Captive Care, and Breeding of Geochelone elegans and Geochelone platynota. Living Art Publishing, Ada, Oklahoma.

Moll, E.O. 1989. Geochelone elegans Indian Star Tortoise, pp. 113-114. In: I.R. Swingland and M.W. Klemens (eds.), The Conservation Biology of Tortoises. Occasional Papers of the IUCN Species Survival Commission (SSC) No. 5. IUCN-The World Conservation Union, Gland, Switzerland.

Vyas, R. 2003. Reptile lore of Gujarat: Association of reptiles with culture of Gujarat State. Herpinstance 1(2): 10-12.

Vyas, R. 2011. Record size of Indian Star Tortoise: Geochelone elegans (Schoepff, 1795). Russian Journal of Herpetology 18: 47-50.

Vyas, R. and B.M. Parasharya. 2000. Distribution and status of the Star Tortoise (Geochelone elegans) in Gujarat State, India. Zoos' Print Journal 15: 239-242. 